\title{
COSTUMES MATRIMONIAIS ENTRE JAPONESES E SEUS DESCENDENTES NO BRASIL ${ }^{1}$
}

\author{
Lúcia Wollet de Mello \\ (Escola Normal Major Juvenal Alvim, Atibaia)
}

No Japão, ao que tudo indica, os padrões relativos ao casamento estão sofrendo profunda transformação, mormente pela influência americana após a última guerra. Por outro lado, pode-se sentir sua "fôrça" no comportamento e nas atitudes dos japonêses e seus descendentes no Brasil, mesmo quando em vias de aculturação.

$\mathrm{Na}$ sociedade japonêsa tradicional, dada a importância atribuída à família, quando o jovem atinge a maioridade, exerce-se sôbre êle forte pressão no sentido de que contraia matrimônio ${ }^{2}$. Esste ato representa a maneira pela qual o indivíduo sem liames (pelo fato de ser solteiro) passa a estabilizar-se, a "criar raízes" pela constituição de seu próprio grupo familial. O celibato só encontra justificativa quando o indivíduo delibera aperfeiçoar-se no plano intelectual, artístico ou filosófico.

No tocante à mulher, compreende-se que a pressão seja ainda maior, sendo-lhe vedado o direito de adquirir propriedades e ter independência econômica; a única via aberta à estabilidade econômica e à posse de propriedade é o casamento. Aliás, pode-se ver a "carreira" feminina como sucessão de dependências da autoridade masculina: a princípio, do pai ou do irmão mais velho, depois do espôso e, finalmente, quando viúva, do tilho mais velho.

Os casamentos devem ser homogâmicos, porquanto se considera que a diversidade de hábitos, usos e costumes impede a adaptação das personalidades em jôgo. Devido a êste pressuposto, na Casa Imperial os casamentos eram feitos na base da consangüinidade.

Quando uma família tem filhos em idade de casar, busca o nakodo ou intermediário ${ }^{3}$, cuja atribuição é contratar casamento entre os membros da própria comunidade ou de comunidades diferentes. Às vêzes exis . tem nakodo por parte da noiva e por parte do noivo ${ }^{4}$, que visitam os pais dos futuros nubentes a fim de proporcionarem ocasiões de os jovens se encontrarem e conhecerem. Êste encontro, chamado miai, pode ter lugar num chá ou num almôço, com a participação dos intermediários. Se os jovens sentem inclinação mútua, os pais se informam a respeito dos antepassados do pretendente: se não houve entre êles pessoas portadoras de lepra, sífijis, moléstias mentais ou qualquer outra doença grave, bem como se não 
existem "eta" ", sapateiro, lixeiro, peixeiro, enfim, pessoas que tenham exercido profissões consideradas pouco nobilitantes em comparação com a agricultura. Torna-se desnecessária esta "busca" quando os jovens são da mesma aldeia ou cidade.

Marca-se, então, o yome-iri (yome, noiva; iri, do verbo iruquer, entrar) ou seja, "a introdução da noiva" no casamento. Nesta ccasião, a noiva veste um quimono especial, confeccionado para tal fim.

O casamento é cerimônia doméstica ${ }^{6}$, realizada na casa do noivo; a ela assiste quase tôda a coletividade, e os nakodo ocupam aí posição de destaque. Consta de três trocas de três doses de sake (bebida alcoólica feita de arroz) entre os noivos e chama-se san-san ku do (três-três, nove vêz.es). Há discursos, comestiveis, libações de sake e canções de casamento. Lavra-se uma espécie de ata, assinada por duas testemunhas (quase sempre os nakodo) e depois registrada na prefeitura.

A nubente passa, então, a viver com a família do marido. Mas se o casamento fracassar (e há motivos previstos pelos quais se pode considerar ım matrimônio fracassado, autorizando o divórcio), haverá o ku fu ni wan, "a devolução da espôsa". Para isso, os cônjuges assinam uma declaração de não mais pretenderem continuar vivendo juntos, que se chama mi ku da ri kan (três linhas verticais e metade da quarta). A declaração é registrada na prefeitura e por ela se dá o ri en ou ủivórcio, (ri, separação, rompimento; eñ, liame, laço). A mulher volta então para a casa dos pais $€$ espera nova oportunidade de contrair núpcias.

Em 1909 chegaram ao Brasil os primeiros 803 imigrantes japonêses que, desembarcando em Santos, se dirigiram para o interior do Estado de São Paulo. Chegaram depois novas levas de imigrantes, sendo que no período de 1924-1933 aportou em nosso país a maior onda imigratória, num total de 110.191 pessoas. A vinda de japonêses começou a decair desde então, cessando pràticamente no período de 1942 a 1950. Pelo censo de 1940, verificou-se que $91,5 \%$ da população japonêsa se estabeleceu no Estado de São Paulo e 5,6\% no Paraná. Vinte e seis municípios paulistas e cinco paranaenses possuem núcleos japonêses.

A lei brasileira relativa à imigração japonêsa restringia-a a "famílias" ou "casais" destinados à lavoura. Contudo, não conseguiu impedir a vinda de indivíduos solteiros que, graças ao ko sei kazu ku (simulação de casamento) conseguiram burlá-la. Segundo esta prática, havia um ajuste entre famílias com filhos casadoiros, simulava-se um casamento e lobtinha-se, nos passaportes, o necessário visto do consulado brasileiro. Aqui chegados, os "casais" realizavami o mi ku da ri kan e o "casamento" estava desfeito.

No decorrer do tempo, porém, os imigrados solteiros começavam a sentir a necessidade de braços femininos nos trabalhos agrícolas. Para obter єspôsa, dirigiam-se, então, aos nakodo que se mantinham em contacto com os 
chefes de família de diferentes regiões do Estado. (Diga-se de passagem que, aqui como no Japão, a função de nakodo não chegou a constituir profissão, mas os indivíduos que a ela se dedicavam recebiam recompensas quer em dinheiro quer em forma de presentes ${ }^{7}$ ). Porém, aqui a situação era diferente: as moças representavam importante fator econômico no trabalho agrícola, sendo valiosíssimo o seu auxílio na economia doméstica, no acúmulo de riqueza, na própria ascensão social do grupo familial, permitindo à família passar do status de colono ao de pequeno sitiante. Por (isso, os pais avaliavam e pediam ao pretendente um preço correspondente à perda representada pela subtração da jovem no trato da terra. Havia noivas no valor de "san contos" ( 3 contos'de réis), "go contos" ( 5 contos) e as mais preciosas valiam "dju contos" (dez contos) 8 .

Se o pai da noiva e o pretendente, por intermédio do nakodo, entravam em entendimento quanto ao valor da noiva, marcava-se a data do miai. Porém, como por vêzes as distâncias eram grandes, uma simples troca de fotografias substituía êste encontro e a data do casamento era logo fixada.

O casamento realizava-se segundo o ritual do san-san $\mid \mathbf{k u}$ do, com a diferença de a noiva não mais usar o clássico quimono e sim vestido branco, véu, grinalda, buquê de flôres de laranjeira, e o noivo, terno à ocidental. Fazia-se o registro do casamento no consulado japonês e às vêzes no cartório civil da localidade, o que, aliás, era bastante raro.

Por outro lado, havendo motivo para divórcio, realizava-se o mi ku da ri kan, que era, também, registrado 'no consulado, e a espôsa voltava para a casa dos pais com os filhos, se os houvesse. Continuava-se, portanto, no Brasil, a fazer a escolha' da noiva nos moldes tradicionais japonêses e a realizar o casamento e o divórcio sob o contrôle de um representante legal japonês que sancionava as/práticas do país de origem. O casamento de japonêses com brasileiros era desencorajado, como é de prever-se.

Apesar do isolamento geográfico, psíquico e cultural em que viviam as populações japonêsas, certos fatôres vieram contribuir para abalar os mores familiais e acarretar a desintegração das práticas prêsas ao casamento, conforme passaremos a examinar.

Os primeiros imigrantes japonêses no Brasil eram considerados súditos do Japão, razão por que os casamentos, nascimentos e óbitos tinham de ser registrados no consulado japonês. Tal situação perdurou até 1924, quando o govêrno imperial publicou novo edito, pelo qual os filhos de japonêses residentes no estrangeiro receberiam a cidadania japonêsa se registrados no consulado no máximo 14 dias após seu nascimento (Jorna! Paulista, 23 de fevereiro de 1957). Pára exercer contrôle sôbre os súditos japonêses no além-mar, subdividia-se a área habitada por êles em regiões, nomeando para cada uma delas um vice-cônsul, incumbido de orientar e controlar tôda atividade da colônia. 
Com a participação do Japão na guerra mundial em 1941, ao lado dos paises do "eixo", romperam-se as relações entre o Brasil e o Japão, cessando o contrôle do govêrno japonês sôbre os seus súditos aqui residentes. Os cônsules e vice-cônsules perderam a sua função, sendo que alguns foram repatriados e outros tiveram de dedicar-se a atividades diferentes. Os registros nos consulados foram suspensos, o que levou os japonêses e seus descendentes a procurarem enquadramento na legislação brasileira.

Outro fator foi a evacução, a que foram obrigadas as populações japonêsas, durante a guerra, de áreas consideradas estratégicas (principalmente a zona litorânea). Essas populações fixaram-se nas proximidades dos grandes centros, como São Paulo, onde amiudaram os contactos com brasileiros.

Ademais, a boa situação econômica alcançada por certas famílias no interior facilitou aos nisei a busca dos canais de ascensão utilizados pelos brasileiros: abandonando as pegadas dos pais na agricultura, optaram pelas profissões liberais. O título de "doutor" favoreceu a ascensão do mulato no Brasil-Colônia e do filho do imigrante no período republicano, permitindo o casamento dos descendentes de ádvenas bem sucedidos com elementos das famílias de "quatrocentos anos". Porém, no caso dos filhos de japonêses, êstes procuram atingir posição de liderança dentro da própria colônia e, na medida em que se observa entre êles o acatamento da opinião dos mais velhos, não buscam, em geral, casamento com elementos das famílias tradicionais brasileiras, uma vez que não estão, êles próprios, interessados na quebra da barreira interposta ao casamento inter-étnico. Contudo, o título de doutor facilita-lhes escolher, dentro da própria colônia, noiva cujos pais estejam em boa situação financeira, facultando-lhes ascensão social mais rápida. Nesta camada, os nakodo não interferem tão decididamente como na dos agricultores, restringindo sua ação a conselhos e sugestões ${ }^{9}$.

Pela participação em "festinhas" e "associações", os nisei têm oportunidade de se encontrar e de desenvolver namôro nos moldes ocidentais: podem sair juntos, ir ao cinema, fazer piqueniques, etc. Algumas vêzes, fazem-no às escondidas dos pais; outras, os pais tomam conhecimento da "iniciativa" e a aceitam, tomando, porém, o necessário cuidado de, no caso de terminar em casamento, proceder, aqui ou no Japão, ao inquérito a respeito dos antepassados do pretendente, a que antes aludimos; finalmente, há casos em que os pais se conformam com tôdas as práticas que normalmente antecedem o casamento nas sociedades ocidentais, mas, na hora dêste, reservam-se o direito de serem os árbitros absolutos ("Meu filho pode namorar a quem quiser; mas na hora de casar, eu escolho a noiva"), preferindo, é claro, e mesmo impondo noiva de sua própria etnia 10 .

Parece que se observa ainda, entre os descendentes de japonêses, uma oscilação entre as duas práticas: a do san-san ku do, que se registra no 
consulado, e a do casamento civil, acompanhado da cerimônia na igreja católica. Pode ser que um casamento não dê certo e que, mesmo realizado no civil, seja desfeito. Neste caso, dada a valorização, na cultura japonêsa, do status de casado, pode-se realizar novo matrimônio pela cerimônia do san-san ku do e registrá-lo no consulado, uma forma de legitimar a nova união perante a comunidade.

No caso de se realizar a cerimônia japonêsa tradicional apenas, sem registro civil, muitas vêzes os parentes da mulher, instruidos por advogados, interferem, pressionando no sentido da legitimação da união no cartório civil, como forma de fazer o marido enfrentar as responsabilidades impostas pela legislação brasileira, não "devolvendo a espôsa" se o matrimônio fracassar.

Finalizando, cumpre observar que os mores japonêses relativos ao casamento têm revelado bastante persistência no Brasil e que é principalmente nas populações agrícolas que o apêgo às expectativas dos issei é mais pronunciado. Na acomodação à nova situação nota-se que, muitas vêzes, a observância da lei brasileira se prende à conveniência que a família da espôsa vê em defender-se contra a possivel devolução desta no caso de um matrimônio sem êxito. Mas há também uma pequena parcela da população japonêsa que exibe atitude ambivalente, realizando o casamento segundo o código civil brasileiro e registrando-o ao mesmo tempo no consulado de seu país.

\section{NOT A S}

1) $\mathrm{Na}$ coleta dos dados aqui reunidos contei com a cooperação do Prof. J. Santana do Carmo, filho de japonêses e professor de japonês. Serviu-me de intérprete em entrevistas com imigrantes que não falavam o português. Graças aos seus profundos conhecimentos da cultura nipônica, pude compreender melhor certos problemas da aculturação dos japonêses.

2) O motivo que me levou a interessar-me pelo assunto aqui abordado foi justamente o fato de ter observado, convivendo icom jovens japonêses, que ao atingirem a idade de 25 ou 26 anos, seus pais e os membros mais velhos de sua comunidade começavam a preocupar-se com seu estado civil de solteiros, acabando, com sua insistência, por induzi-los ao matrimônio. Esta pressão, que observei ser forte, fêz-me pensar na persistência de um padrão nipônico mesmo entre descendentes de japonêses que pareciam mais libertos e aparentemente, pelo menos, em franco caminho de aculturação.

3) A respeito dos "nakodo" ou "nakaudo" diz Douglas G. Haring ("Japan and the Japanese", in Ralph Linton (ed.) Most of the World, N. York, 1950): "Os casamentos tradicionalmente são arranjados pelo conselho familial, do qual os futuros noivos não participam. Uma pessoa casada, talvez um parente do mesmo sexo que o candidato, é escolhida como intermediária. Auxiliados pelos mexericos, os intermediários que represen- 
tam diferentes famílias, se encontram e discutem os possíveis casamentos. Os intermediários investigam a familia de cada pretendente, indagam de seu status social e econômico, educação, gostos pessoais e hábitos, saúde e provável compatibilidade de cada candidato, e finalmente averiguam os antecedentes da família com relação à lepra, sífilis, tuberculose e crime. Os intermediários... são sempre, permanentemente, responsáveis pelo novo lar. Fracasse o casamento em virtude de circunstâncias que não foram devidamente consideradas por um intermediário relapso e o negociador faltoso sofrerá rigoroso ostracismo social" (págs. 484-49). Mais adiante diz o mesmo autor: "O intermediário é indispensável em tôdas as negociações que 'envolvem relações com pessoas que não pertençam à família" (pág. 851).

4) Para uma descrição bastante detalhada do casamento no Japão, cf. Edward Norbeck, Takashima. A Japanese Fishing Community, Salt Lake City, 1954, págs. 174-185, se bem que, evidentemente, possa haver diferenças de detalhes quanto às práticas na zona rural e urbana, bem como nas diversas regiões do Japão. Quanto ao aspecto de que ora tratamos, diz êste Autor que "em alguns casos, ambas as casas implicadas (do rapaz e da moça) contratam intermediários, de sorte que as negociações sâo feitas entre dois pares de baishakunin (ou nakodo)" (pág. 175).

5) Os "eta" constituem um minoria altamente desprestigiada no Japão, um verdadeiro grupo pária. Antes de sua liberação, em 1871, eram obrigados a viver em quarteirões determinados e a observar regulamentos especiais quanto ao vestuário e ao comportamento. Depois disso, embora legalmente "emancipados", permaneceram uma minoria socialmente subordinada e desprezada, tida como inerentemente estranha e inferior. São abertamente discriminados nas escolas, ocupações e casamento. Vivem numa comunidade socialmente segregada e isolada. Não caberia aqui tratar da origem dêste grupo. Contudo, parece que se prende ao exercício de certas profissões (como, por exemplo, a de magarefe) que, quando se deu a difusão do Budismo no Japão, foram condenadas.

6) Segundo Douglas G. Haring (op. cit.), alguns casamentos modernos, à imitação do costume cristão, são realizados num altar shintoísta ou num templo budista, mas de preferência no primeiro, em virtude de sua associação com a fertilidade e a vida (enquanto os templos budistas são associados à morte e aos funerais). Também êste autor dá uma versão um pouco diferente da cerimônia matrimonial: "Para legalizar um casamento, o pai da noiva obtém seu registro de nascimento na delegacia de polícia e o entrega ao pai do noivo, que o deposita em seu próprio koseki (registro de família) na delegacia de polícia apropriada. Desde então a noiva é um membro legal da família do noivo, sujeita ao contrôle do chefe da casa. Seus parentes afins podem divorciá-la, mesmo contra a vontade do marido, caso ela lhes desagrade" (pág. 849). Prosseguindo, relata êste autor que por isso são comuns os casamentos experimentais, nos quais a cerimônia que acima relatamos é realizada: o casal passa a viver junto, mas o pai do noivo adia a transferência do registro até que se tenha provado o êxito do casamento. Na classe pobre, muitas vêzes se dispensa a cerimônia, e, segundo Douglas G. Haring, "na zona rural, numerosos estudos revelam coincidência quase universal entre a data do registro do casamento e a do nascimento do primeiro filho" (pág. 849).

7) Edward Norbeck refere-se à existência de intermediários profissionais, que, entretanto, não eram apreciados em Takashima, preferindo-se o emprêgo de "amadores". Diz ainda que nessa comunidade se conside- 
rava quase como dever humanitário atuar, pelo menos uma vez na vida, como nakodo, havendo mesmo pessoas que se destacavam neste papel, tornando-se conhecidas pela sua habilidade, interêsse etc. Aliás, refere-se à importante contribuição feminina neste sentido e informa que, mesmo no caso de se encarregar um homem de servir de intermediário, a espôsa sempre o ajudava, muito embora êle recebesse maior honra que ela por ocasião da festa do casamento. (Op. cit., pág. 175).

8) Edward Norbeck (op. cit.) se refere ao yuino, ou dote de noivado em dinheiro, apresentado pela família do noivo à da noiva. Cabe ao nakodo, depois do miai, caso o futuro casamento interesse ainda a ambas as famílias depois dêste encontro, estabelecer em quanto montará o dote. O yuino é entregue à família da noiva de maneira formal, altamente ritualizada, riquíssima em detalhes simbólicos, em três somas de dinheiro, cada qual embrulhada em separado. Uma delas se destina, tradicionalmente, às vestes de casamento, da noiva; outra é para o sake, e a terceira para o peixe, êstes últimos a serem servidos na festa realizada no dia em que a noiva deixa sua casa. (Para uma visão mais completa de todo êste ritual, v. págs. 177-8). Parece, portanto, que, mesmo diferindo as duas práticas, existe já no Japão um precedente, pelo menos formal, de se "pagar" um preço pela noiva, preço êste negociado pelo nakodo.

9) Seiichi Izumi ("Aspectos da vida dos japonêses no Brasil", Memórias do I Painel Nipo-Brasileiro, Escola de Sociologia e Política de São Paulo, São Paulo, 1956, Tomo II, págs. 40-41) diz o seguinte: “...não sabemos com exatidão a ocorrência de intercasamentos entre os elementos da etnia japonêsa e os de outras etnias; todavia, nos últimos dois ou três anos, a incidência parece ser intensa... Em têrmos gerais, o status da mulher brasileira que desposa marido japonês é 'igual' ou 'superior' ao do marido. Na zona rural, o status do marido brasileiro que desposa mulher japonêsa é muitas vêzes, bem 'inferior' ao da mulher. Há indícios de que quanto mais alto o nível de instrução escolar, maior é o índice de intercasamento. Por exemplo, entre os filhos de japonêses que se formaram nas faculdades de medicina, cêrca da metade casou-se com elementos de outras etnias".

10) Hiroshi Saito ("O suicídio entre imigrantes japonêses e seus descendentes no Estado de São Paulo", Sociologia, vol. XV, n.o 2, 1953, págs. 109-130), cita, entre 74 suicídios e 4 tentativas, 7 casos em que o motivo apontado foi "amor com brasileiros". Trata-se de 5 rapazes e 2 moças, com idades variando entre 16 e 22 anos. Embora, nestes casos, a oposição dos pais pareça ter-se prendido ao nível social dos brasileiros em aprêço (no caso dos rapazes, duas das pretendentes eram prostitutas, duas eram empregadas domésticas da própria casa e uma, professôra primária) diz Saito: "O namôro de nipo-brasileiros com os 'brasileiros' é, muitas vêzes, alvo de censura por parte dos pais que vêem no casamento misto um acontecimento imprevisto nos seus padrões de comportamento, e assim, ante a barreira de oposição dos pais, os jovens nipo-brasileiros são forçados a fazer a escolha: ou fugir com a pessoa amada ou suicidar-se" (pág. 119). 